\title{
Sustainability Intervention Mechanisms for Managing Road Freight Transport Externalities: A Systematic Literature Review
}

\author{
Abiye Tob-Ogu ${ }^{1}{ }^{(\mathbb{D}}$, Niraj Kumar ${ }^{2}$, John Cullen ${ }^{1}$ and Erica E. F. Ballantyne ${ }^{1, *}$ (]) \\ 1 Faculty of Social Science, Sheffield University Management School, University of Sheffield, \\ Sheffield S10 2TN, UK; a.tob-ogu@sheffield.ac.uk (A.T.-O.); john.cullen@sheffield.ac.uk (J.C.) \\ 2 University of Liverpool Management School, Chatham Street, Liverpool L69 7ZH, UK; \\ niraj.kumar@liverpool.ac.uk \\ * Correspondence: e.e.ballantyne@sheffield.ac.uk
}

Received: 30 April 2018; Accepted: 4 June 2018; Published: 8 June 2018

\begin{abstract}
With road freight transport continuing to dominate global freight transport operations, there is increasing pressure on the freight transport industry and its stakeholders to address concerns over its sustainability. This paper adopts a systematic review to examine the academic literature on road freight transport sustainability between 2001 and 2018. Using content and thematic analysis, the paper identifies and categorises sustainability intervention mechanisms providing useful insights on key research applications areas and continental distribution of sustainable road freight transport (SRFT) research. In addition to the six-overarching sustainability intervention mechanism themes identified: decoupling, Information and Communications Technology (ICT), modality, operations, policy, and other, future research can explore the effectiveness of different interventions mechanisms identified in this study to improve sustainable practices across different continents.
\end{abstract}

Keywords: road freight; sustainability; intervention mechanisms; systematic review; externalities

\section{Introduction}

Despite its importance to economic growth and prosperity, there are valid concerns relating to the sustainability of road freight transportation in terms of safety, efficiency, and health implications. These concerns are reflected in the contemporary road freight transport literature [1-6].

Accordingly, there is increasing pressure on stakeholders to address externalities emanating from freight transport operations across a variety of landscapes including urban, inter-urban, and rural landscapes. For example, in Europe, road freight transport sustainability is a priority for the European Commission (EC) with initiatives like MERCURIO, ERTRAC, KOMODA, and FIDEUS highlighting the commitment of the supranational and State level actors to addressing road freight transport sustainability. Academically, authors [6-8] have explored various sustainability initiatives in the road freight sector with insights on policy approaches, multi-stakeholder involvement, and modal integration planning. These initiatives represent some of the different mechanisms employed to intervene and tackle road freight externalities. For example, the literature investigates and discusses the idea of green corridor infrastructure for road freight transportation [9], other studies [1,10,11] have explored applications of information and communication technology (ICT) to aid sustainable road freight operations, whilst other studies discuss policy loopholes and freight energy management strategies [12].

Intervention mechanisms represent efforts, tools, and approaches that are theory or practice informed to address specific challenges. These capture not only the vitality of research inquiries into 
sustainable road freight transport but also highlight the complexity of the field. A resulting implication of this complexity is a lack of knowledge congruence which can negatively impact the development of research collaboration and efficiency [13]. Further, the literature is yet to address the impact of contextual limitations on the adoption of specific intervention mechanisms and this can have interesting impact for strategic planning amongst freight transport stakeholders. For example, green corridor initiatives can be considered as Pan-European, with conceptual and pragmatic acceptance across the European community. However, limitations relating to infrastructure or regional mobility may affect their adoption outside of Europe, for instance the absence of such regional cooperation in Africa or Southern America limits the pragmatism of such an initiative in these regions and thus highlights potential knowledge gaps concerning relationships between contexts and intervention mechanisms. The purpose of this paper extends to examining the focus of the literature as well as providing some guidance for optimising future research and practice across different regions. In this regard, the objective of this paper is to provide a synthesized account of the literature on sustainable road freight transport (SRFT) interventions offering some insight on the main SRFT research streams, taxonomies, as well as insights on the contextual implications for SRFT intervention mechanisms. Such outcomes can improve future research synergy and collaboration, support strategic planning and offer useful reference for future research.

To achieve our objective, the following research questions were posed:

1. What are the main intervention mechanisms advanced in peer-reviewed publications on sustainable road freight transport?

2. What implications do regional contexts have on the adoption of different intervention mechanisms?

Addressing these questions through a critical review of the literature will advance the significance of sustainable road freight transport as a critical area of research in the logistics and supply chain sustainability literature. Additionally, it will address current knowledge gaps on the relationship between intervention mechanisms and geographical contexts, with implications for future research and practice. The rest of this paper is organised as follows: Section 2 presents a discussion of systematic literature reviews in management research; Sections 3 and 4 describe the methodology and analysis approaches for the study; whilst Section 5 presents the study discussions. Finally, our concluding statements and directions for future research are presented in Section 6.

\section{Systematic Literature Reviews}

The use of systematic reviews in the social sciences and specifically management research has significantly developed in the last decade with increasing acceptance across ontological and epistemological divides [14]. As knowledge converges and develops towards complementary methods in the social sciences, the pillars of reliability and apposition are increasingly important [15]. It has been advocated that systematic reviews help to map relevant intellectual territories that identify how and where the literature base can benefit from further studies, i.e., the identification of research gaps [14]. Whereas others take a more instructive approach [16], calling for systematic reviews to support the literature's account of contextual factors that need to be integrated into management research.

The importance of these issues is addressed by [17] who underline the use of systematic reviews to enable transparency, inclusivity, heuristics, and explanation in the review process. Accordingly, the importance of systematic reviews of the extant literature on SRFT related studies has been previously emphasized [4] who highlight the benefits to the development of research in this area. However, since Perego's review [4], there has been little done to update the literature in this area and a recent review [18], focuses more on the general urban logistics function rather than road freight transport specifically. SRFT research requires targeted and collaborative synergies to address the ubiquitous challenges faced and a systematic review of the data can give useful funneling for identifying specific trends as well as collaborative scope in SRFT research. 


\section{Methodology}

The importance of a review protocol prior to conducting a systematic review of the literature and cited its usefulness for mitigating biases in the review process has been emphasised [17]. The literature review protocol was implemented in four stages, i.e., design, review, selection and analysis.

\subsection{Design of Review Protocol}

Accordingly, 3 review team members jointly developed a protocol with inputs from discussions with academic and industry experts in road freight logistics within and outside the UK. The purpose of this was to enhance the rigour and evidence base of the review outcomes. The protocol tied the review objectives to the processes establishing the data sources, plausible databases, inclusion and exclusion criteria, search string techniques and acceptance schedule (Table 1).

Table 1. Review Protocol.

\begin{tabular}{|c|c|c|c|c|}
\hline & \multicolumn{2}{|c|}{ Inclusion and Exclusion Criteria } & Databases & Data Sources \\
\hline & Inclusion & Exclusion & \multirow{5}{*}{$\begin{array}{l}\text { Taylor \& Francis } \\
\text { Google Scholar } \\
\text { Science Direct } \\
\text { Web of Science } \\
\text { Sage } \\
\text { Emerald }\end{array}$} & \multirow{5}{*}{$\begin{array}{l}\text { Online (Soft) } \\
\text { Print (Hard) }\end{array}$} \\
\hline Timeframe & Between 2001 and February 2018 & Outside $2001-2018$ & & \\
\hline Type & Peer reviewed & $\begin{array}{l}\text { Non-peer reviewed, books, } \\
\text { conference papers }\end{array}$ & & \\
\hline Topic & $\begin{array}{l}\text { Road freight transport, road logistics, } \\
\text { sustainable road freight transport }\end{array}$ & $\begin{array}{l}\text { Non-sustainability, } \\
\text { Non-road freight transport }\end{array}$ & & \\
\hline Language & English or English Translate & Non-English & & \\
\hline \multirow{2}{*}{ Reviewer's Initials } & \multirow{2}{*}{ Paper no. } & & \multicolumn{2}{|c|}{ Decision (Please tick) } \\
\hline & & & Accept/Rationale & Reject/Rationale \\
\hline Search Technique & \multicolumn{4}{|l|}{ Boolean, Verbatim and Word combinations: } \\
\hline
\end{tabular}

The protocol was not considered a rigid guide and iteration supported modification as the actual review process progressed. Although SRFT publications go back many decades, our focus was on identifying contemporary and updated intervention mechanisms. The cut off timeline for the review was initially set between the years 2001 and 2016 and later extended to 2018 (February), following further reviews and feedback. This period coincided with uptake in technology as well as commencement of the millennium development goals (MDGs), which underlined a global outlook to sustainability across different sectors. Practical constraints relating to time, feasibility, access to materials and review scope also informed the design and modification of the protocol. For example, although we are aware of useful grey publications, we omitted these from the review due to considerations on quality and reliability (peer-review process improves the value of the report) and practicality (impossible to review all publications or gain access to regional publications across different continents).

\subsection{Review and Selection}

Following the review and affirmation of the agreed review protocol, six databases; ScienceDirect ${ }^{\circledR}$, Emerald $^{\circledR}$, Taylor and Francis ${ }^{\circledR}$, Sage ${ }^{\circledR}$, Web of Science ${ }^{\circledR}$ and Google Scholar ${ }^{\circledR}$, were identified as suitable for conducting the literature search. This was informed by learning from similar literature reviews and the need to represent the complexity of SRFT publications. Test searches revealed gaps in scope of individual databases and we observed that the incorporation of more databases offered greater opportunities for capturing the latitude of potential SRFT literature. Simple operator and Boolean search methods were combined to execute the search using different phrases and strings to implement the search.

In the first instance, the review process was designed to follow a funneling procedure, moving from broad references to smaller and restrictive (Boolean) criterion as the review progressed. Search strings and keys works including: "sustainable freight"; "green freight"; "road freight"; "sustain* 
freight"; "green freight"; and "road freight", "sustain* logistics*", were used to search these databases with a combined yield of 2265 hits in 2016 and an extra 88 hits in 2018. After a review of titles and over 300 abstracts from the first searches, a few adjustments were made to the protocol. For example, the phrase "road freight" was removed from the 'list of search strings' due to its extremely large sample when used by itself without 'green' or 'sustainability' included in the search. Boolean logic was applied to combine keywords like "Road freight" and "sustain*", improving the focus of the returned results. In many instances, some of the results from these search strings failed to address any sustainability issues and included other issues besides road freight transport. This led to the rejection of 1158 papers, which were deemed irrelevant based on a 1st screen scanning of the titles and abstracts. An important learning from this process was the critical role that titles, abstracts and keywords play in influencing publication visibility and readership of peer-reviewed material.

Following further searches and 'hit' reviews, a decision was made to exclude Google scholar from the 'search database' because of duplicity and source credibility. For example, a preliminary search conducted using the 'sustainable freight' string returned just over a thousand results with Google scholar accounting for over $90 \%$ of the results (Figure 1). Closer scrutiny of the results revealed that over 200 of the results from Google Scholar were repeated on several occasions within the database with varying citations from both peer-review and bogus sources. Furthermore, we established that much of the 'peer-reviewed' references within the Google Scholar batch were already reported by the other databases. Whilst it is plausible to suggest that the exclusion of the Google Scholar database may raise questions about the scope of the evidence incorporated in the review, it was also important that the review was conducted within robust but qualitative parameters. This is particularly important when the "peer review" inclusion criterion is taken into consideration.

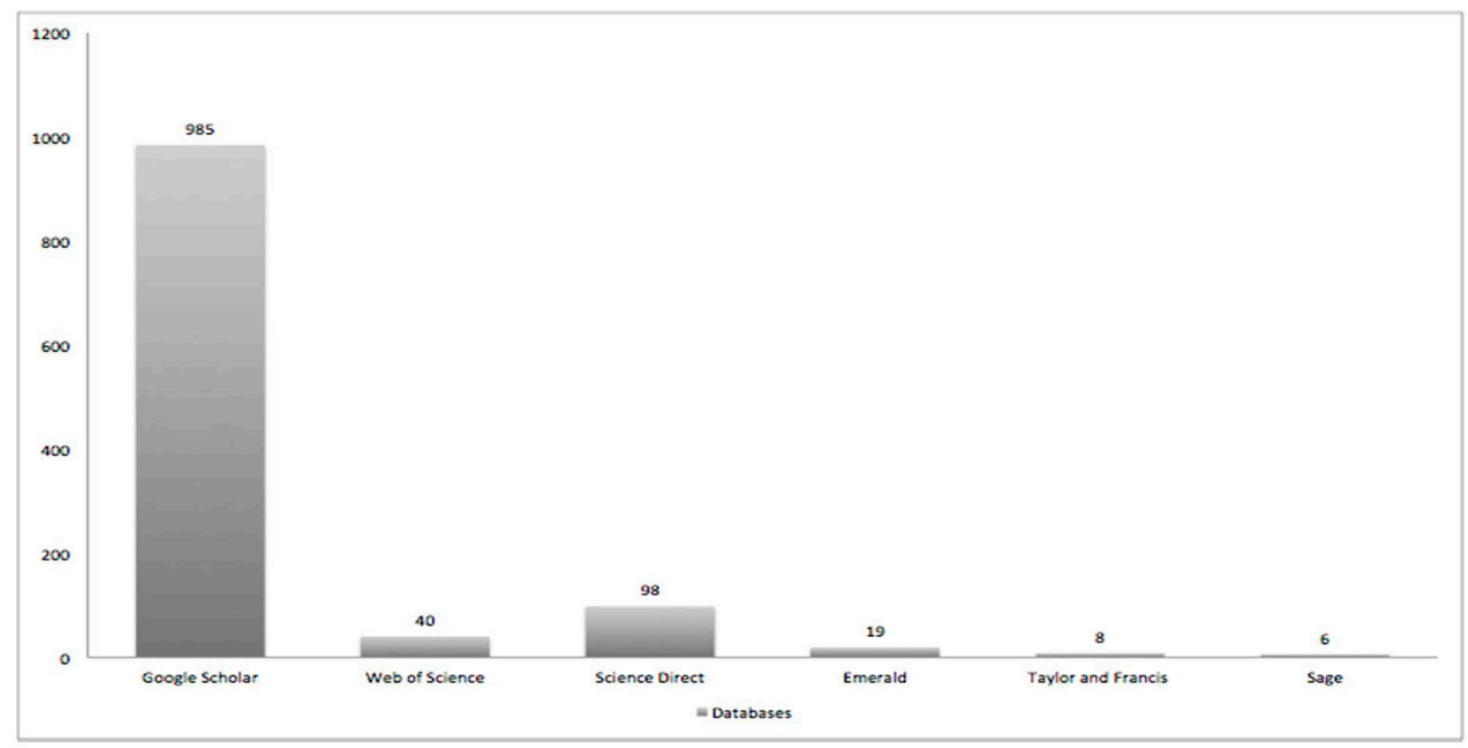

Figure 1. Chart illustrating initial database 'hits' for "Sustainable Freight" string.

Progressively, search terms were replicated across the remaining databases with additional strings used to streamline the searches. As captured by the protocol, the focus was on peer-reviewed material in published sources and a total of 403 hits were returned across 8 re-organized searches. After screening for duplicates and relevance, a total of 168 materials were accepted for further review. A 3rd stage review of the abstracts, introduction and publication type saw an elimination of a further 54 materials which were books, conference proceedings or items that did not materially discuss the related subject of "sustainability in road freight transport". A total of 98 journal articles from 44 different journal titles were finally accepted for inclusion in the review report (Figure 2 and Supplementary Materials: Appendix A1. 


\section{Journals}

Transportation Research Part E: Logistics and Transportation Science Transportation Research Part D: Transport and Environment
Tran

Transportation Research Part C: Emerging Technologies

Transportation Research Part A: Policy and Practice Transportation Planning and Technology
Transportation Journal

Transport Reviews

Transport Policy
Technological Forecasting and Social Change

Sustainability

Spanish Journal of Agricultural Research Research in Transportation Economics

Research in Transportation Business and Management Proceedings of the Institution of Mechanical Engineers, Part D: Proceedings of the Institution of Mechanical Engineers, Part C:...

Networks and Spatial Economics

Management of Environmental Quality: An International Journal

Journal of Transport Geography

Journal of the Air \& Waste Management Association Journal of Scheduling

Journal of Manufacturing Technology Management

Journal of Infrastructure Development

Journal of Environmental Planning and Management Journal of Environmental Economics and Management

Journal of Cleaner Production International Journal of Sustainable Transportation

International Journal of Sustainable Transport

International Journal of Productivity and Performance Management International Journal of Production Economics

International Journal of Physical Distribution \& Logistics International Journal of Logistics Research and Applications

International Journal of Logistics Management

European Transport Research Review European Journal of Operational Research

Energy Policy
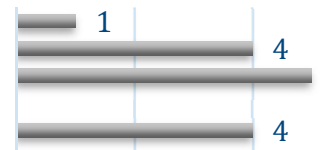

1
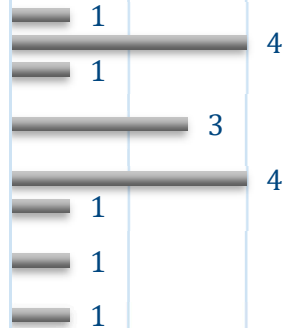

1
1

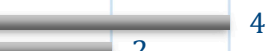

1

\section{1}

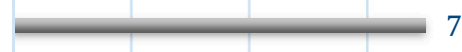

1

1

1

1

3

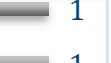

1

1

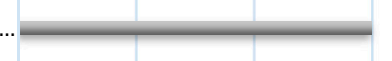

6

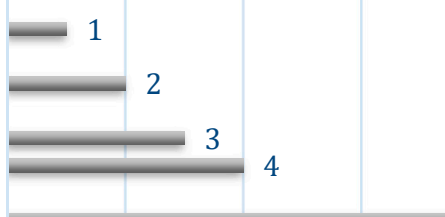

Energy and Environment

Energy

Computers in Industry Cogent Engineering

Benchmarking: An International Journal

Advances in Mechanical Engineering

Accident Analysis and Prevention
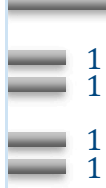

2

2

1

$0 \quad 2$

4

6

Figure 2. Final Journal Selection. 


\section{Analysis}

Using the context, intervention, mechanisms, and outcome (CIMO) framework [17], each article was carefully evaluated in line with the review objectives and we adopted a combination of content and thematic analyses to review, interrogate, and organise the data for reporting (Supplementary Materials: Appendix A1). Topics covered by the corpus extended across road freight transport performance, design, and policy, highlighting the diverse literature spectrum. NVivo11 ${ }^{\mathrm{TM}}$ [19] was used to query and review the selected papers, exploring each paper in detail, identifying the principal focus of each paper, key arguments, theoretical underpinnings, methodological design, and key findings. The coding function on NVivo11 ${ }^{\mathrm{TM}}$, was used to create and further query themes. Where we observed papers as addressing multiple themes, we allocated them to the category where the predominant discourse was aligned based on frequency of keywords used, authors' depiction as content frequency, analogies, and sorting. The use of NVivo11 ${ }^{\mathrm{TM}}$ and multiple reviewers not only helped reduced perceptive bias, NVivo11 ${ }^{\mathrm{TM}}$ also supported the speed of the data query process to identify topical links, thematic clusters, and alignments. For example, the frequency and cluster analysis tools in NVivo $11^{\mathrm{TM}}$ were used to identify key words and usage contexts, creating an objective output for further analysis. It was also used to support our Jaccard co-efficiency testing to validate the emergent themes from the data.

The process was also influenced by previous knowledge about the literature on road freight transport, for example we are conversant with papers from authors who examined the literature to develop an online benchmarking tool for freight transport operations in the EU, Switzerland, and Norway [20]; papers which investigated the use of ICT in road freight operations, highlighting $\mathrm{CO}_{2}$ emissions reductions and efficiency gains from the use of ICT in road freight operations [1,3]. This prior knowledge contributed designation of themes although some reported themes were emergent from the coding process.

To support the originality index of the extracted themes, we conducted a Jaccard coefficient similarity test to distinguish the depth of correlation between the different themes [21]. The highest coding similarities involved articles and codes discussing ICT, modality, and operations, with combinations of 0.276 (ICT/modality), 0.143 (ICT/operations), and 0.115 (modality/others), respectively. With the low similarity indexes between the different theme categories, we accepted the interpreted theme categories as distinct themes capturing various intervention mechanisms from the reviewed literature.

In total, six themes were identified in the process: Policy, operations (design and process); modality (uni-modality, co-modality, synchro and inter-modality); decoupling, ICT; and 'others' (land use, UCCs, reporting, and measurement systems). Figure 3 shows the distribution of the articles according to the intervening mechanisms that they addressed. Operations, policy and modality themes commanded higher scholastic attention and accounted the majority of the 98 papers reviewed. 


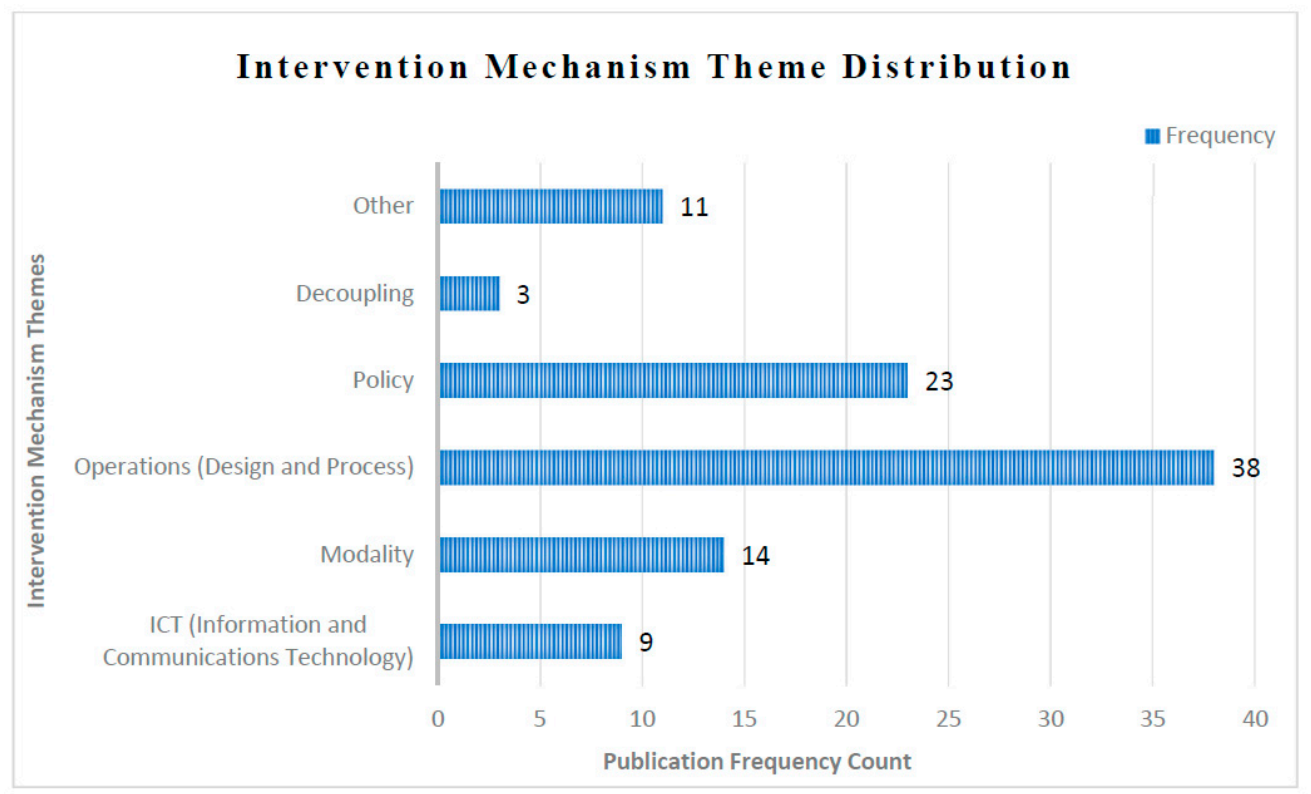

Figure 3. Road Freight Transport Sustainability Intervention Mechanisms.

\section{Discussion}

There is a growing focus on road freight transport sustainability with a variety of approaches to mitigate its consequences. In Figure 4, the Chart highlights the overall publication trend for papers in this area and although the figures for 2018 suggest a further decline, this is entirely due to the cut off period for the database selection (See Table 1). The analysis of the reviewed literature highlights several interventions, which are classified, summarized (Table 2) and discussed below in themed categories.

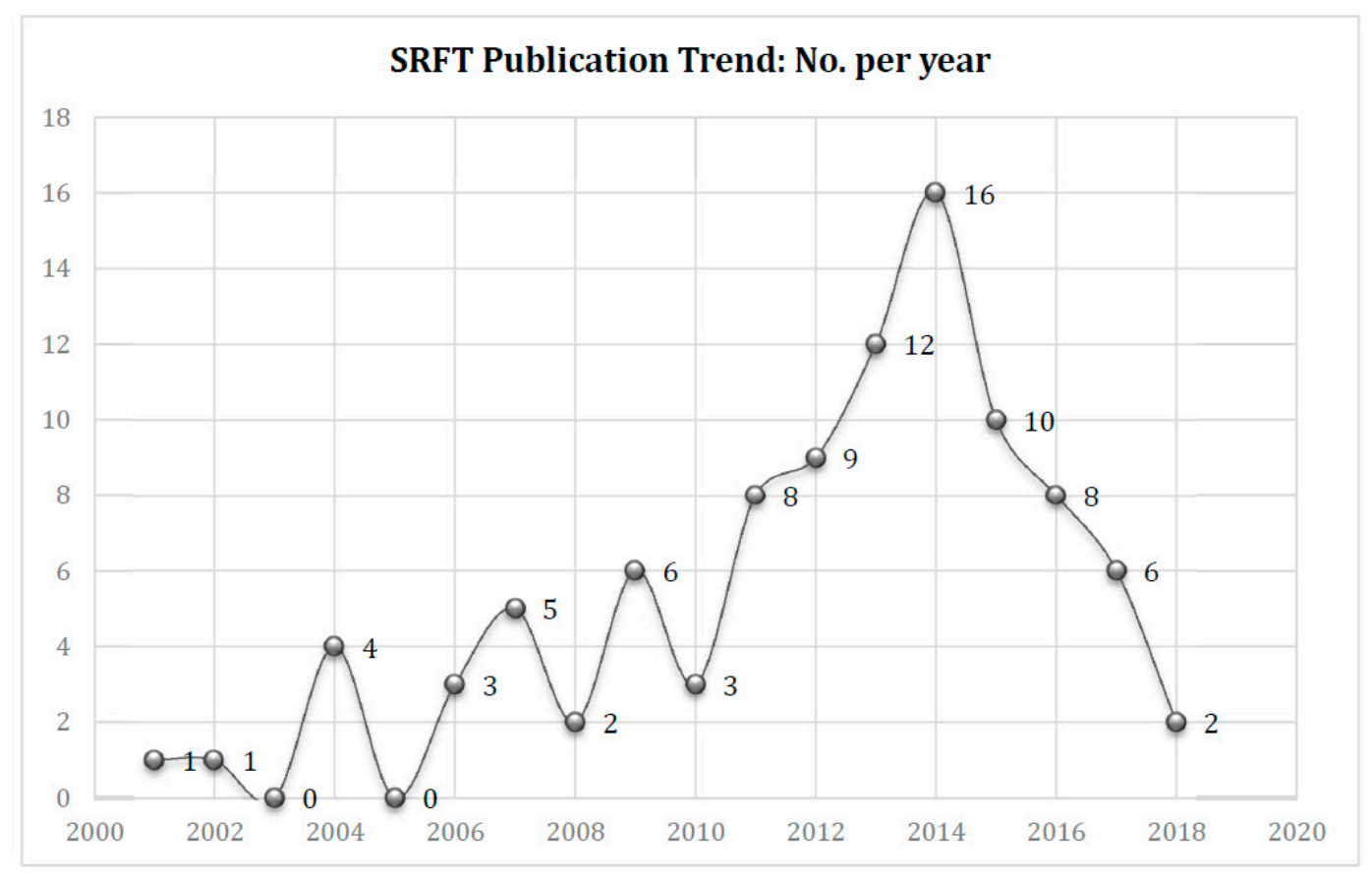

Figure 4. Number of sustainable road freight transport (SRFT) publications per year. 
Table 2. Intervention Themes, Key Authors, and Topics Summary.

\begin{tabular}{|c|c|c|c|}
\hline Theme & Key Authors & Topics & No. \\
\hline $\begin{array}{l}\text { Information and } \\
\text { Communications } \\
\text { Technology (ICT) }\end{array}$ & $\begin{array}{l}\text { Wang et al., 2015; Sternberg et al., 2014; } \\
\text { Marchet et al., 2012; Davies et al., } 2007\end{array}$ & $\begin{array}{l}\text { ICT use for } \mathrm{CO}_{2} \text { reduction, } \\
\text { ICT use for intermodal transport, Efficiency } \\
\text { benefits of ICT use }\end{array}$ & 9 \\
\hline Decoupling & $\begin{array}{l}\text { Alises et al., 2014; Liimatainen and Pollanen, 2013; } \\
\text { McKinnon } 2007\end{array}$ & $\begin{array}{l}\text { Decomposition analysis, Impact evidence, } \\
\text { Policy roles, and impact }\end{array}$ & 3 \\
\hline Modality & $\begin{array}{l}\text { Li et al., 2015; Macharis et al., 2011; Caris et al., 2008; } \\
\text { Winebrake et al., } 2008\end{array}$ & $\begin{array}{l}\text { Dynamic modelling for intermodal freight, } \\
\text { Decision Support Systems (DSS) for } \\
\text { optimising intermodal freight, Energy and } \\
\text { emissions trade-offs in road freight, } \\
\text { Co-modality }\end{array}$ & 14 \\
\hline Operations & $\begin{array}{l}\text { Newnam and Goode, 2015; Li et al., 2015; } \\
\text { Midgley et al., 2015; Liimatainen et al., 2014; } \\
\text { Schiffer and Walther, 2018, Wang et al., 2014; } \\
\text { Palsson and Kovacs, 2014; Ando and Taniguchi, } 2006\end{array}$ & $\begin{array}{l}\text { Socio-technical perspectives of externalities, } \\
\text { Alternative fuels, } \\
\text { Regenerative braking mechanics, } \\
\text { Management strategies, Time travel, } \\
\text { reliability, and routing }\end{array}$ & 38 \\
\hline Policy & $\begin{array}{l}\text { M'raihi et al., 2015; Stelling, 2014; } \\
\text { Ballantyne et al., 2013; Pieyck and McKinnon, 2010; } \\
\text { Eom et al., 2009; Dablanc, 2007; Steenhof et al., } 2006\end{array}$ & $\begin{array}{l}\text { Emissions and influencing factors, } \\
\text { Stakeholder needs and local council } \\
\text { planning, emission ELKS factors and } \\
\text { planning horizons, cost measures and } \\
\text { practitioner approaches, decomposition } \\
\text { analysis, and modal shifts }\end{array}$ & 23 \\
\hline Others & $\begin{array}{l}\text { Khorheh et al., 2015; Demir et al., 2014; } \\
\text { Islam et al., 2013; Carballo-Panela et al., } 2012\end{array}$ & $\begin{array}{l}\text { Green corridors, congestion planning, land } \\
\text { use and urban freight, and performance } \\
\text { benchmarking tools }\end{array}$ & 11 \\
\hline
\end{tabular}

\subsection{Intervention Themes}

\subsubsection{Operations}

The operations theme represents interventions that focus on optimising SRFT operations through a combination of equipment and process design initiatives. Articles in this category explored intervention mechanisms across strategic, tactical, and operational levels. Topics relating to fleet management strategies [22-25], routing [26-28], vehicular design and load utility [29,30], fuel type trade-offs [31-33], and costs [34], were within this purview. Some of the main contributions in this area include the importance of assigning the 'right' vehicle to the 'right' areas, advocating fleet management models that account for environmental distinctions as a means for addressing $\mathrm{CO}_{2}$ emissions [22]. Other studies identified significant energy index value $\left(\mathrm{EI}_{\mathrm{V}}\right)$ gains of $9-17 \%$ from modelling hydraulic controls using the greedy optimization technique to investigate driving cycles, highlighting potential benefits heavy goods vehicle (HGV) design as an SRFT intervention [29].

In terms of fuel choices and implications, Li et al.'s study provides useful insight into the potential for alternative fuels in road freight operations [31]. They model consumption and demand using a cost-optimisation strategy to forecast consumption, projecting long-term reliance on diesel and gasoline fuels, which they estimate will still be responsible for over $70 \%$ of freight fuel by 2030. Of significant interest and implication for future research in this area, was the identification that resource constraints for other fuel forms remained a principal limitation to bigger decline on gasoline and diesel dependence. Although routing efficiencies remain of key concern to road freight transport scholars, developing contributions in this area include modelling for routing optimisation, Original Equipment Manufacturing (OEM) design insight, energy, and load decisions as well as the development of DSS tools for routing and location planning [26]. The role of decision support tools to aid management decision-making in terms of fleet vehicle selection and optimal combination strategies is still an area with knowledge gaps on applications at different strategic levels.

Overall, we identified that an increasingly salient feature of many articles in this category was the reference to, or combination with information systems technology elements as a fundamental of the operations optimisation models. This was confirmed by the Jaccard coefficient results and underlined elements of interrelationships between different themes $[27,35,36]$. 


\title{
5.1.2. Policy
}

Policy captures State driven mechanisms for addressing road freight challenges. Critically, interventions cover local, regional, and national levels of applications and this was interpreted to involve more complexities compared to Decoupling strategies that were specifically national or supranational in scope. Much of the literature in this category focused on the urban freight problem $[7,37-40]$. Some key topical issues under this theme explored robustness of policy mechanisms, for example one study advocate a 'new stakeholder' approach for addressing the urban freight problem at local council levels [7]. This was to cater for conflicting objectives that often pitch businesses and councils at opposing divides. Like Klumpp's application of the Jevon paradox (rebound) theory to examine SRFT failure reasons from an operations perspective [41], a previous study had reviewed the USA environment and highlighted some crucial policy misconstructions in terms of the efficiency metrics for road freight management advising;

\begin{abstract}
"Policymakers should be careful when using existing freight elasticity estimates in the literature to estimate the HGV rebound effect. Aside from general caveats associated with these indirect measures of the rebound effect, freight elasticity estimates are influenced by a number of "factors of variability" categorized by the specific nature of the shipping activity, the macroeconomic influences involved, and the measurement tools used to assess elasticities. Ignoring these factors may lead to biased results when applying the literature to a specific policy analysis case"-[12], (pp. 258)
\end{abstract}

The rebound effect refers to increased resource consumption because of relative efficiencies in performance, i.e., the difference between projected and actual energy savings as a direct correlate of increased efficiencies [12,42]. The arguments put forward suggests that policy makers need to go beyond energy efficiency saving metrics to actual energy demand reduction measures. It is advocated that measurement adjustments be made to policy projections for energy efficiencies in the road freight sector, where rebound effects can be as high as $24 \%$.

Similarly, another study models the same problem in Tunisia and explores policy strategies for addressing the road freight emissions challenge [43]. They proffer a combination of incentivising arrangements and fiscal strategies as useful for addressing these challenges. Furthermore, they compare policy options in terms of decoupling as a mechanism for intervention as opposed to other incentivising and fiscal arrangements, with a conclusion that the peculiar economic and political realities in the context would significantly affect the viability of such a strategy. This point is particularly instructive in the evaluation of strategic options for different countries, with developing economies less likely to effectively pursue policy strategies that de-emphasize their main revenue and growth processes. Another research saw modelled a policy quadrant to advance some policy directions for road freight transport planning using empirics from Sweden [37]. Of keynote is the requirement for a combination of legal, economic, societal, and knowledge instruments at national/local levels, which will support direction, income, infrastructure, and behavioural adaptations, respectively required to meet future targets. Some key contributions in this area include best practice collations, strategic planning tools, and incentivising approaches for SRFT and cooperation amongst stakeholders.

\subsubsection{Modality}

The modality theme addresses the means and mode of transport employed to effect freight mobility. Under this theme, the main topics focus on the combination with or substitution of road freight transport with other modes of transport. In terms of substitution, the literature acknowledges the critical qualities of flexibility, speed, and time from road freight transport, with implications for last mile dependency on road freight for the foreseeable future [44-48]. However, the literature presents a variety of modal combinations for addressing congestion, emissions, and cost concerns unimodal road freight transport $[46,49,50]$. The terms 'co-modality', 'multimodality' and 'synchro or intermodality' are used to represent modal options within the literature. Co-modality is defined as the efficient use of different modes [51], whilst Ruiz-Garcia et al. differentiate between intermodality and 
multimodality, stating that multimodality implies using different transport modes and administration, whilst intermodality refers to the integration of administrative and transfer process of freight shipment across different transport modes [52]. Some operations aspects addressed in this category include packaging designs, intermodal component requirements, and modal integration $[47,50]$.

Intermodality is a central theme of the literature in this category; all the thirteen papers reviewed under this theme discussed intermodality in some degree. This is perhaps driven by the rationale that intermodality provides the most reasonable compromise for managing the emissions and congestion challenge of road freight [53]. Rail and water modal combinations are considered as best complements or alternatives for road freight transport although the literature acknowledges that for many shipments from international sources, water freight transport is already an inalienable part of the freight transport chain since it is the common export and import option for shipments between countries [48]. However, the literature also notes intermodality as a complex model and highlights some common constraints to its operationalisation: infrastructure [37,43,54]; decision support systems [50,54]; interoperability and planning [10,52,55]; and transitioning implementation [48]. Contributions in this area include costs modelling for different modal combinations, environmental benefits, and integration efficiencies stemming from modal combinations.

Overall, the availability or investment in infrastructure like railways, jetties, hubs, and freight corridors are prerequisites for modality-based interventions. The absence of these can undermine or restrict the usefulness of modal interventions. Future directions in this area may focus on decision support tools to aid transition, interoperability, and planning with significant elements of policy drivers in this regard.

\subsubsection{Decoupling}

Unlike policy initiatives, decoupling as a policy strategy can only be pursued as a national or supranational strategy mechanism and therefore excludes independent interventions at local council levels [56]. Decoupling strategies established as national or supranational policy approaches, aimed at separating economic growth from freight as a measure of curbing externalities from freight [6].

Traditionally, decoupling measures have focused on freight intensity (tonne-km), using modal split, vehicle utilisation and emissions as metric units for GDP comparisons, economic planning and forecasting $[6,57,58]$. Although results have been positive in countries like the UK and Spain, this is still an emerging area within the literature and key concerns extend to its 'emissions-shifting' and measurement metrics ambiguities. Additionally, its applicability as a viable mechanism in developing countries has been rejected and recent political upheavals in Europe and the USA could further exert limitations on strategies that de-emphasize manufacturing as a means of curbing freight externalities [43,57].

Perhaps a major contribution of studies in this area is the development of decomposition analysis frameworks for investigating road freight and GDP correlations, contributing to progressive insight and alignment between specific industry and freight intensity [6,56,57]. Freight policy strategists at regional and national levels can benefit from these studies, with prospects of integrating context specific economic structures for carbon reporting, haulage distances and modal choice splits into existing GDP aggregate measures.

\subsubsection{Information and Communications Technology}

ICT accounted for ten (10\%) of the articles reviewed although many of the other articles were cross-themed with ICT. We constructed ICT to encompass both information systems (IS) and information technology (IT), referring to combinations of hard and soft connectivity tools that support communication exchanges, remote monitoring and performance management within freight transport operations $[1,3,59]$. Some papers adapt taxonomies for identifying and classifying road freight transport ICT systems, although Wang et al.'s taxonomy provides the most comprehensive overview for deconstructing ICT mechanisms for road freight transport operations $[1,59]$. 
Accordingly, ICT is conceptualised as consisting of three main components, the software components applications, including operating systems; the hardware components; and the information component $[1,51,59]$. Addressing issues around connectivity, network relationship management, enterprise processes, and asset management $[3,60,61]$, ICT is commonly presented as positively impacting road freight transport through operational efficiencies in road freight $[1,62]$, providing social benefits [3,10], cost reduction and effectiveness [55], driver working time, and administration time reductions [3]. Critically, only Button et al. [10] and Sternberg et al.'s [3] papers explicitly addresses the social aspects of ICT's potential in terms of road freight transport sustainability. There is perhaps more need for targeted research enquiries on the application of ICT to address social issues in road freight transport.

The bulk of the literature focuses on environmental and economic aspects ICT use for road freight transport sustainability $[10,55,61-63]$. The topical issues of ICT adoption drivers and barriers is explored within the literature, with size, management capabilities, topologies, interoperability, and industry structure emerging as some critical areas of concurrent research inquiries $[51,59,63]$. Some key contributions under this theme include safety, emissions modelling, and operations integrations among freight stakeholders.

Despite the increased research uptake in this area, significant opportunities exist for contributions around ICT mechanisms for achieving social sustainability measures as well as the development of decision support system (DSS) tools for road freight efficiency and emission planning. We identified that although there is a growing interest in the area of "big data" and "automated or driverless freight transport", none of the results in our search discussed these as key topics. This perhaps points to gaps in the literature or limitations of publication abstracts and it is hoped that future research will address these gaps.

\subsubsection{Others}

This generic category encompasses studies that focus on, performance and reporting tools [64,65], land use and infrastructure [38,66], and freight transport reviews $[44,67,68]$. For example, the concept of 'green corridors' as a Pan-European intervention mechanism for road freight transport sustainability is addressed [66]. Green corridors require dedicated infrastructure for freight mobility, each of which would incorporate inland waterways, road, rail, and shipping. As a strategy, 'green corridors' encompasses all of policy, ICT, intermodal and operations mechanisms that create dedicated freight infrastructure frameworks that are ecologically and environmentally friendly. Additionally, one of the papers, considers the infrastructure challenge from a more social perspective, exploring the illegal use of parking bays and the implications for policy makers and managers, where illegal demand is fuelling unauthorised parking with disruptive outcomes [38].

Finally, in terms of reviews, Khorheh et al., introduce an interesting perspective to the externality problem, highlighting some direct and indirect impacts of road freight transport. They also highlight taxation and incentive planning as some socio-economic mechanisms, in addition to information technology and cultural instrumentations [44]. Their paper provides an extensive review of emissions, discussing concurrent operational framework tools for managing emissions in road freight transport and is comparable to a previous work [69]. Studies under this theme have contributed to research guidance, strategic conceptualisations, and urban consolidation centre strategies.

\subsection{Regional Context Implications}

In terms of contexts and implications a coordinate analysis of the papers focused on identifying the empirics of the papers or stated geographical locality of the papers reviewed (Table 3 and Figure 5). 
Table 3. Geographic distribution according to continental regions.

\begin{tabular}{cc}
\hline $\begin{array}{c}\text { Distribution of SFT Research Focus } \\
\text { According to Continents }\end{array}$ & $\begin{array}{c}\text { Count of Distribution of SFT Research } \\
\text { Focus According to Continents }\end{array}$ \\
\hline Africa & 4 \\
Australia & 4 \\
Europe & 63 \\
Generic & 13 \\
North America & 8 \\
South America & 1 \\
South East Asia & 5 \\
\hline Total & 98 \\
\hline
\end{tabular}

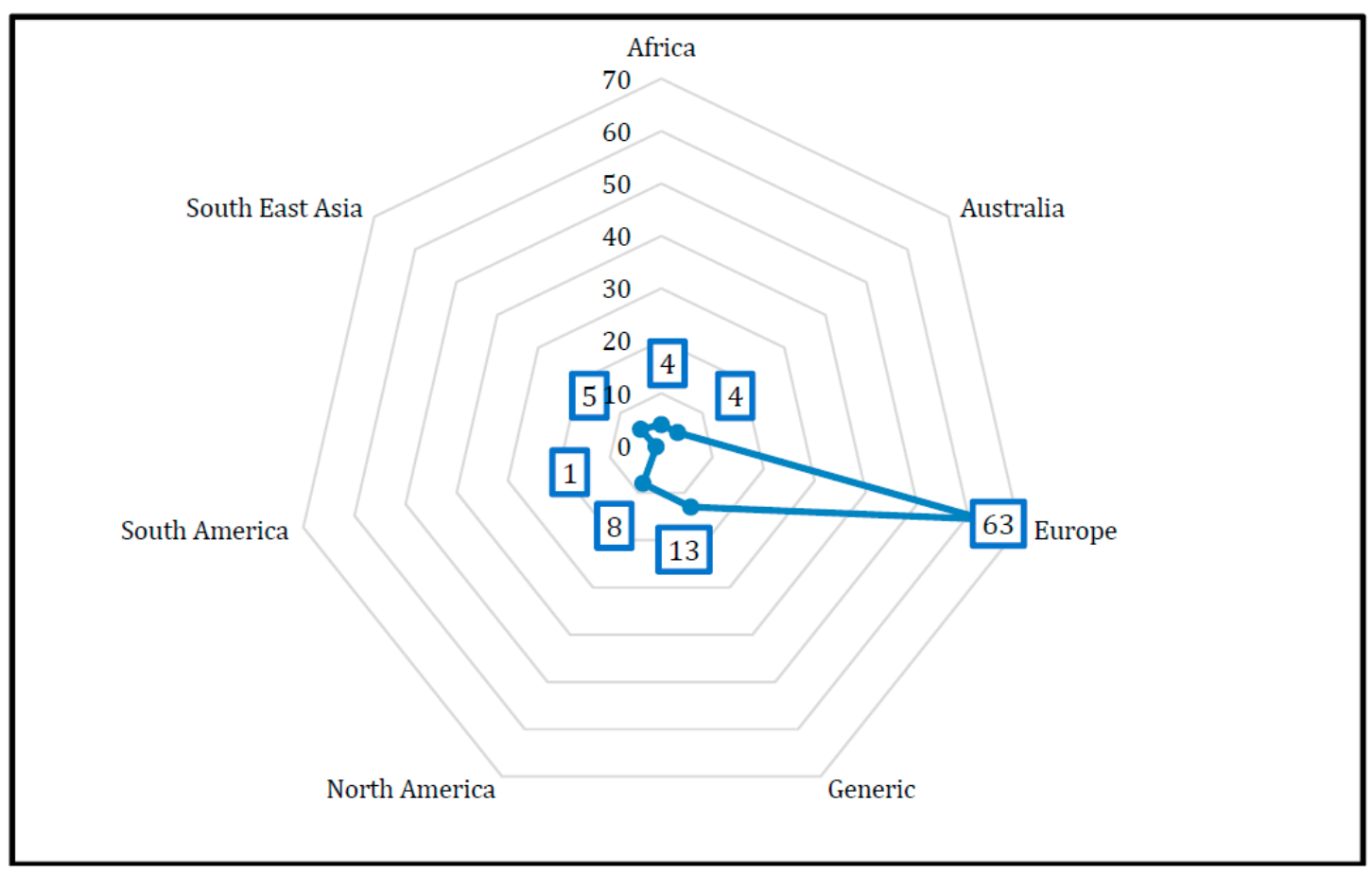

Figure 5. Radar Chart showing coordinates of publications.

As depicted by Figure 5, there is significant disproportionality in the regional coordinates of the articles reviewed. Perhaps influenced by database locations and web analytics settings, Europe unsurprisingly accounted for the majority (63) of the papers reviewed, however, there were interesting patterns observed across the different categories reviewed. All the different intervention mechanism themes had been examined within European contexts, with decoupling being the exclusive preserve of Europe. All three papers that examined decoupling as a subject matter were based on European empirics $[6,57,70]$. It may be useful for future research to explore how regional frameworks like the European Commission or European Union are influencing policy at State levels in comparison to other regional blocs outside of Europe. Further, the geographical differences observed provide a useful justification for future research around benchmarking and best practice sharing from one country or region to another. This area is yet to be explored in the literature and there may be opportunities for impact in terms of transferable exchanges between firms in this area.

With regards to publication trend analysis, besides the geographical distribution trend discussed above, no other specific predictive trend was apparent in the papers reviewed. For example, although the earliest paper focused on ICT [10], there was a 7-year gap between that and the next ICT paper, 
however subsequent ICT papers did not follow any timeline specification. For the other themes, we observed a closer distribution of publications across the different years. From 2002, operations focused research seemed the most stable stream of research with an average of two papers per year, although we observed that publications in this area have averaged four papers per year since 2014 . The decoupling stream seems to have lost traction, as there has been no publication since 2014. Perhaps the notable pattern seems to be the steady decline in publications from a peak of 16 papers in 2014 to six in 2017 (Figure 4). This underlines the need for more focused SRFT research.

Our categorisation also highlighted some heterogeneity between modality and operations. For operations, routing and scheduling, facility planning, fleet design, and energy consumption were the most common topics within the European literature [30,36,71]. In contrast, the only paper from Africa that was reviewed under these categories explored a myriad of bottlenecks such as corruption, insecurity, and infrastructure limitations to road freight operations in Nigeria [24]. There is scope for future studies to explore and model optimal operations and modality frameworks for countries in Africa and South America.

As depicted by Figure 3 and Table 4, policy and operations are the most common intervention mechanisms for road freight sustainability. Although the literature suggests that European and American contexts are more likely to produce SRFT research initiatives compared to Asian and African nations [43,72], there are still knowledge gaps in relation to establishing factors that drive sustainable road freight policies by way of comparative studies across different continental regions. Additionally, whilst some policy papers highlight stakeholder engagement decision challenges [7], none of the papers we reviewed were focused on addressing multi-criteria decision making problems at policy level. This is an important yet emerging area of interest and future studies in this area may hold useful learning for policy makers and researchers in terms of decision making optimization, knowledge transfer, and cross-national collaboration.

Table 4. Pivot matrix of intervention themes per continental regions.

\begin{tabular}{lcccccccc}
\hline \multirow{2}{*}{ Intervention Mechanisms } & \multicolumn{7}{c}{ Continental Regions } \\
\cline { 2 - 9 } & AF & AS & AU & EU & GN & NA & SA & Total \\
\hline Decoupling & 0 & 0 & 0 & 3 & 0 & 0 & 0 & 3 \\
ICT (Information \& Communications Technology) & 0 & 0 & 0 & 8 & 0 & 1 & 0 & 9 \\
Modality (Inter and Co-modality) & 1 & 0 & 0 & 8 & 3 & 2 & 0 & 13 \\
Operations (Design and Process) & 1 & 3 & 1 & 26 & 4 & 2 & 0 & 38 \\
Other & 0 & 1 & 2 & 5 & 2 & 1 & 0 & 10 \\
Policy & 2 & 1 & 1 & 13 & 4 & 2 & 1 & 23 \\
\hline Grand Total & 4 & 5 & 4 & 63 & 13 & 8 & 1 & 98 \\
\hline
\end{tabular}

ICT is increasingly gaining preference amongst management and researchers, who identify its potential to support sustainable road freight across social, environmental, and economic frameworks [1,3]. Whilst papers that focus specifically on ICT as a freight intervention mechanism are limited, much of operations and modality themed papers recognize the propensity of ICT to support initiatives in these areas [61,73]. For example, Harris et al. linked the success of $33 \mathrm{EU}$ intermodal framework projects to ICT technology [51]. This position is consistent with the findings from previous studies [48,52], where the successes of intermodal interventions were project as dependent on ICT breakthroughs. ICT offers a robust scope for exploring the multifaceted challenges associated with road freight transport in terms of both existing technology and the range of problems addressed. Whilst requiring significant cost investment to implement, ICT offers benefits in terms of performance control and monitoring [59]. Control in the sense that management have the complete command over its deployment and usage within their operations, with extended benefit for society. Despite the costs, it provides a more attractive option for addressing performance and sustainability issues within road freight operations. 
As a developing pathway within the interventions approaches, the literature in this area is still relatively sparse, particularly regarding social outcomes from ICT deployment for road freight transport sustainability. Case studies and related in-depth methodologies may be adopted to help promote understanding on adoption drivers, barriers and derived benefits from ICT use for road freight transport operations. Our findings highlight potential areas for future research contributions by way of extending current models and approaches to South American, African, and Asian contexts. Future research may adopt exploratory approaches to understand drivers and barriers to interventions or their effectiveness in relation to contexts.

\section{Conclusions}

The aim of this paper has been to provide a concise overview of the extant literature on road freight transport sustainability, identifying and categorising intervention mechanisms as well as reporting on intervention alignments with continental regions. In addressing the two research questions, this study has identified six theme categories (decoupling, ICT, modality, operations, policy, and others) within which the extant literature on road freight transport sustainability can be characterized. Combining content and thematic analyses approaches, extracted themes were subjected to Jaccard's coefficient similarity test in order to validate the originality of each identified theme. In this regard, we believe our study has contributed to the future research design agenda in this area with clear pathways for future studies to explore and make contributions in this contemporary, yet complex area of academic interest.

Most notably, the results of the systematic literature review revealed that over a third (thirty-eight) of the papers reviewed featured research around operations (design and process). Often the main contributions of articles falling under the operations theme were around matching the vehicle to the specific area in which it operates, and utilising fleet management models for addressing emissions. Similarly, policy driven mechanisms featured highly in the articles reviewed (twenty-three), although with urban freight dominating the academic literature in this area, there is clearly opportunity for future research to expand beyond the urban context.

The geographical distribution of the articles reviewed (2001-2018) was also particularly revealing, highlighting that sixty-five percent of papers reviewed identified with Europe as their geographic region. Furthermore, papers that identify with decoupling as a policy strategy intervention are exclusively associated with Europe, although there has been no recent publication under this theme. Perhaps there is opportunity for enquiries in this area, exploring the potential for implementing decoupling strategies in North America and Asia. Also, future studies may investigate the effectiveness of decoupling strategies across Europe as the UK prepares to depart from the European Union.

Furthermore, as per regional contexts and mechanisms, we noted correlations between mechanisms and continental coordinates. Our continental analysis suggests that SRFT research has relatively low international collaborative applications, a common problem with many sustainability practices that are occurring in continental silos. However, we recognise that externality impacts are not always local and perhaps more needs to be done to improve sustainable practices across different continents to drive collective and effective impact that will improve our understanding of different interventions across different contexts. We are confident that our findings make significant contributions in a complex field of study by categorising the extant literature in some simple yet objective modus that will support the development of the field as well as support future research classifications. These findings will act as further stimulus for research in this area of SRFT.

Supplementary Materials: The following are available online at http:/ /www.mdpi.com/2071-1050/10/6/1923/s1. Appendix A (1 and 2) contain details (schedule of reviewed papers and search log records) that are supplemental to the main text and have been referenced in the discussion. The information within the appendix can be crucial to the understanding of the themes discussed in the paper. 
Acknowledgments: This research was partially supported by the project "Promoting Sustainable Freight Transport in Urban Contexts: Policy and Decision-Making Approaches (ProSFeT)", "funded by the H2020-MSCA-RISE-2016 programme (Grant Number: 734909)" and the EU-India Research \& Innovation Partnership for efficient and sustainable freight transportation (REINVEST) project "funded by the European Union 'EU-India Research and Innovation Partnership' (Grant Number: R/142842)".

Conflicts of Interest: The authors declare no conflict of interest.

\section{References}

1. Wang, Y.; Sanchez-Rodrigues, V.; Leighton, E. The use of ICT in road freight transport for CO2 reductionAn exploratory study of the UK's grocery retail industry. Int. J. Logist. Manag. 2015, 26, 2-29. [CrossRef]

2. Palsson, H.; Kovacs, G. Reducing transport emissions: A reaction to stakeholder pressure or a strategy to increase competitive advantage. Int. J. Phys. Distrib. Logist. Manag. 2014, 44, 284-304. [CrossRef]

3. Sternberg, H.; Prockl, G.; Holmström, J. The efficiency potential of ICT in haulier operations. Comput. Ind. 2014, 65, 1161-1168. [CrossRef]

4. Perego, A.; Perotti, S.; Mangiaracina, R. ICT for logistics and freight transportation: A literature review and research agenda. Int. J. Phys. Distrib. Logist. Manag. 2011, 41, 457-483. [CrossRef]

5. McKinnon, A.C.; Piecyk, M.I. Measurement of CO2 emissions from road freight transport: A review of UK experience. Energy Policy 2009, 37, 3733-3742. [CrossRef]

6. McKinnon, A.C. Decoupling of Road Freight Transport and Economic Growth Trends in the UK: An Exploratory Analysis. Transp. Rev. 2007, 27, 37-64. [CrossRef]

7. Ballantyne, E.E.F.; Lindholm, M.; Whiteing, A.E. A comparative study of urban freight transport planning: Addressing stakeholder needs. J. Transp. Geogr. 2013, 32, 93-101. [CrossRef]

8. Richardson, B.C. Sustainable transport: Analysis frameworks. J. Transp. Geogr. 2005, 13, 29-39. [CrossRef]

9. Clausen, I.U.; Geiger, C.; Behmer, C. Green Corridors by Means of ICT Applications. Procedia Soc. Behav. Sci. 2012, 48, 1877-1886. [CrossRef]

10. Button, K.; Doyle, E.; Stough, R. Intelligent transport systems in commercial fleet management: A study of short term economic benefits. Transp. Plan. Technol. 2001, 24, 155-170. [CrossRef]

11. Tob-Ogu, A.; Kumar, N.; Cullen, J. ICT adoption in road freight transport in Nigeria-A case study of the petroleum downstream sector. Technol. Forecast. Soc. Chang. 2018, 131, 240-252. [CrossRef]

12. Winebrake, J.J.; Green, E.H.; Comer, B.; Corbett, J.J.; Froman, S. Estimating the direct rebound effect for on-road freight transportation. Energy Policy 2012, 48, 252-259. [CrossRef]

13. Grant, R.M.; Baden-Fuller, C. A Knowledge-Based Theory of Inter-Firm Collaboration. Acad. Manag. Proc. 1995, 17-21. [CrossRef]

14. Tranfield, D.; Denyer, D.; Smart, P. Towards a methodology for developing evidence-informed management knowledge by means of systematic review. Br. J. Manag. 2003, 14, 207-222. [CrossRef]

15. Van Wee, B.; Banister, D. How to Write a Literature Review Paper? Transp. Rev. 2016, 36, 278-288.

16. Morrell, K. The narrative of "evidence based" management: A polemic. J. Manag. Stud. 2008, 45, 613-635. [CrossRef]

17. Denyer, D.; Tranfield, D. Producing a systematic literature review. In The SAGE Handbook of Organisational Research Methods; Buchanan, D., Bryman, A., Eds.; Sage Publications: London, UK, 2009; pp. 671-689.

18. Lagorio, A.; Pinto, R.; Golini, R. Research in urban logistics: A systematic literature review. Int. J. Phys. Distrib. Logist. Manag. 2016, 46, 908-931. [CrossRef]

19. NVivo Qualitative Data Analysis Software; QSR International Pty Ltd.: Doncaster, VIC, Australia, 2016.

20. Islam, D.M.Z.; Zunder, T.H.; Jorna, R. Performance evaluation of an online benchmarking tool for European freight transport chains. Benchmark. Int. J. 2013, 20, 233-250.

21. Bouchard, M.; Jousselme, A.L.; Doré, P.E. A proof for the positive definiteness of the Jaccard index matrix. Int. J. Approx. Reason. 2013, 54, 615-626. [CrossRef]

22. Velazquez-Martinez, J.C.; Fransoo, J.C.; Blanco, E.E.; Valenzuela-Ocana, K.B. A new statistical method of assigning vehicles to delivery areas for CO2 emissions reduction. Transp. Res. Part D Transp. Environ. 2016, 43, 133-144. [CrossRef]

23. Allen, J.; Browne, M.; Cherrett, T. Investigating relationships between road freight transport, facility location, logistics management and urban form. J. Transp. Geogr. 2012, 24, 45-57. [CrossRef] 
24. Ubogu, A.E.; Ariyo, J.A.; Mamman, M. Port-hinterland trucking constraints in Nigeria. J. Transp. Geogr. 2011, 19, 106-114. [CrossRef]

25. McKinnon, A.C.; Ge, Y. The potential for reducing empty running by trucks: A retrospective analysis. Int. J. Phys. Distrib. Logist. Manag. 2006, 36, 391-410. [CrossRef]

26. Ehmke, J.F.; Campbell, A.M.; Thomas, B.W. Vehicle Routing to Minimize Time-Dependent Emissions in Urban Areas. Eur. J. Oper. Res. 2015, 251, 478-494. [CrossRef]

27. Fleischmann, B.; Gnutzmann, S.; Sandvoß, E. Dynamic Vehicle Routing Based on Online Traffic Information. Transp. Sci. 2004, 38, 420-433. [CrossRef]

28. Haughton, M.A. Route reoptimization's impact on delivery efficiency. Transp. Res. Part E Logist. Transp. Rev. 2002, 38, 53-63. [CrossRef]

29. Midgley, W.J.; Cebon, D. Control of a hydraulic regenerative braking system for a heavy goods vehicle. Proc. Inst. Mech. Eng. Part D J. Automobile Eng. 2015, 230, 1338-1350. [CrossRef]

30. Olsson, J.; Woxenius, J. Localisation of freight consolidation centres serving small road hauliers in a wider urban area: Barriers for more efficient freight deliveries in Gothenburg. J. Transp. Geogr. 2014, 34, 25-33. [CrossRef]

31. Li, W.; Dai, Y.; Ma, L.; Hao, H.; Lu, H.; Albinson, R.; Li, Z. Oil-saving pathways until 2030 for road freight transportation in China based on a cost-optimization model. Energy 2015, 86, 369-384. [CrossRef]

32. Gilpin, G.; Hanssen, O.J.; Czerwinski, J. Biodiesel's and advanced exhaust aftertreatment's combined effect on global warming and air pollution in EU road-freight transport. J. Clean. Prod. 2014, 78, 84-93. [CrossRef]

33. Demir, E.; Bektas, T.; Laporte, G. A comparative analysis of several vehicle emission models for road freight transportation. Transp. Res. Part D Transp. Environ. 2011, 16, 347-357. [CrossRef]

34. Lammgard, C.; Andersson, D. Environmental considerations and trade-offs in purchasing of transportation services. Res. Transp. Bus. Manag. 2014, 10, 45-52. [CrossRef]

35. Sternberg, H.; Germann, T.; Klaas-Wissing, T. Who controls the fleet? Initial insights into road freight transport planning and control from an industrial network perspective. Int. J. Logist. Res. Appl. 2013, 16, 493-505. [CrossRef]

36. Pérez-Martínez, P.J. The vehicle approach for freight road transport energy and environmental analysis in Spain. Eur. Transp. Res. Rev. 2009, 1, 75-85. [CrossRef]

37. Stelling, P. Policy instruments for reducing $\mathrm{CO}_{2}$-emissions from the Swedish freight transport sector. Res. Transp. Bus. Manag. 2014, 12, 47-54. [CrossRef]

38. Alho, A.R.; de Abreu e Silva, J. Analyzing the relation between land-use/urban freight operations and the need for dedicated infrastructure/enforcement-Application to the city of Lisbon. Res. Transp. Bus. Manag. 2014, 11, 85-97. [CrossRef]

39. Liimatainen, H.; Stenholm, P.; Tapio, P.; McKinnon, A.C. Energy efficiency practices among road freight hauliers. Energy Policy 2012, 50, 833-842. [CrossRef]

40. Dablanc, L. Goods transport in large European cities: Difficult to organize, difficult to modernize. Transp. Res. Part A Policy Pract. 2007, 41, 280-285. [CrossRef]

41. Klumpp, M. To Green or Not to Green: A Political, Economic and Social Analysis for the Past Failure of Green Logistics. Sustainability 2016, 8, 441. [CrossRef]

42. Matos, F.J.F.; Silva, F.J.F. The rebound effect on road freight transport: Empirical evidence from Portugal. Energy Policy 2011, 39, 2833-2841. [CrossRef]

43. M'raihi, R.; Mraihi, T.; Harizi, R.; Taoufik Bouzidi, M. Carbon emissions growth and road freight: Analysis of the influencing factors in Tunisia. Transp. Policy 2015, 42, 121-129. [CrossRef]

44. Khorheh, M.A.; Moisiadis, F.; Davarzani, H. Socio-environmental performance of transport systems. Manag. Environ. Qual. Int. J. 2015, 26, 810-825.

45. Winebrake, J.J.; Corbett, J.J.; Falzarano, A.; Hawker, S.J.; Korfmacher, K.; Ketha, S.; Zilora, S. Assessing Energy, Environmental, and Economic Tradeoffs in Intermodal Freight Transportation. J. Air Waste Manag. Assoc. 2008, 58, 37-41. [CrossRef]

46. Kim, N.S.; Van Wee, B. Assessment of $\mathrm{CO}_{2}$ emissions for truck-only and rail-based intermodal freight systems in Europe. Transp. Plan. Technol. 2009, 32, 313-333. [CrossRef]

47. Arnold, P.; Peeters, D.; Thomas, I. Modelling a rail/road intermodal transportation system. Transp. Res. Part E Logist. Transp. Rev. 2004, 40, 255-270. [CrossRef] 
48. Bontekoning, Y.M.; Priemus, H. Breakthrough innovations in intermodal freight transport. Transp. Plan. Technol. 2004, 27, 335-345. [CrossRef]

49. Li, L.; Negenborn, R.R.; De Schutter, B. Intermodal freight transport planning-A receding horizon control approach. Transp. Res. Part C Emerg. Technol. 2015, 60, 77-95. [CrossRef]

50. Macharis, C.; Caris, A.; Jourquin, B.; Pekin, E. A decision support framework for intermodal transport policy. Eur. Transp. Res. Rev. 2011, 3, 167-178. [CrossRef]

51. Harris, I.; Wang, Y.; Wang, H. ICT in multimodal transport and technological trends: Unleashing potential for the future. Int. J. Prod. Econ. 2015, 159, 88-103. [CrossRef]

52. Ruiz-Garcia, L.; Barreiro, P.; Rodriguez-Bermejo, J.; Robla, J.I. Review. Monitoring the intermodal, refrigerated transport of fruit using sensor networks. Span. J. Agric. Res. 2007, 5, 142-156. [CrossRef]

53. Sanchez-Rodrigues, V.; Cowburn, J.; Potter, A.; Naim, M.; Whiteing, A. Developing “Extra Distance" as a measure for the evaluation of road freight transport performance. Int. J. Product. Perform. Manag. 2014, 63, 822-840. [CrossRef]

54. Caris, A.; Macharis, C.; Janssens, G.K. Planning Problems in Intermodal Freight Transport: Accomplishments and Prospects. Transp. Plan. Technol. 2008, 31, 277-302. [CrossRef]

55. Marchet, G.; Perotti, S.; Mangiaracina, R. Modelling the impacts of ICT adoption for inter-modal transportation. Int. J. Phys. Distrib. Logist. Manag. 2012, 42, 110-127. [CrossRef]

56. Liimatainen, H.; Pollanen, M. The impact of sectoral economic development on the energy efficiency and CO2 emissions of road freight transport. Transp. Policy 2013, 27, 150-157. [CrossRef]

57. Alises, A.; Vassallo, J.M.; Guzman, A.F. Road freight transport decoupling: A comparative analysis between the United Kingdom and Spain. Transp. Policy 2014, 32, 186-193. [CrossRef]

58. Steenhof, P.; Woudsma, C.; Sparling, E. Greenhouse gas emissions and the surface transport of freight in Canada. Transp. Res. Part D Transp. Environ. 2006, 11, 369-376. [CrossRef]

59. Marchet, G.; Perego, A.; Perotti, S. An exploratory study of ICT adoption in the Italian freight transportation industry. Int. J. Phys. Distrib. Logist. Manag. 2009, 39, 785-812. [CrossRef]

60. Crainic, T.G.; Ricciardi, N.; Storchi, G. Models for Evaluating and Planning City Logistics Systems. Transp. Sci. 2009, 43, 432-454. [CrossRef]

61. Ando, N.; Taniguchi, E. Travel time reliability in vehicle routing and scheduling with time windows. Netw. Spat. Econ. 2006, 6, 293-311. [CrossRef]

62. Davies, I.; Mason, R.; Lalwani, C. Assessing the impact of ICT on UK general haulage companies. Int. J. Prod. Econ. 2007, 106, 12-27. [CrossRef]

63. Walker, G.H.; Manson, A. Telematics, urban freight logistics and low carbon road networks. J. Transp. Geogr. 2014, 37, 74-81. [CrossRef]

64. Kinnear, S.; Rose, A.; Rolfe, J. Emissions Reporting in the Australian Road Freight Transport Sector: Is There a Better Method than the Default Option? Int. J. Sustain. Transp. 2014, 9, 93-102. [CrossRef]

65. Islam, D.M.Z.; Fabian Meier, J.; Aditjandra, P.T.; Zunder, T.H.; Pace, G. Logistics and supply chain management. Res. Transp. Econ. 2013, 41, 3-16. [CrossRef]

66. Carballo-Penela, A.; Mateo-Mantecon, I.; Domenech, J.L.; Coto-Millán, P. From the motorways of the sea to the green corridors' carbon footprint: The case of a port in Spain. J. Environ. Plan. Manag. 2012, 55, 765-782. [CrossRef]

67. Marchet, G.; Melacini, M.; Perotti, S. Environmental sustainability in logistics and freight transportation: A literature review and research agenda. J. Manuf. Technol. Manag. 2014, 25, 775-811. [CrossRef]

68. Demir, E.; Bektas, T.; Laporte, G. A review of recent research on green road freight transportation. Eur. J. Oper. Res. 2014, 237, 775-793. [CrossRef]

69. Demir, E.; Huang, Y.; Scholts, S.; Van Woensel, T. A selected review on the negative externalities of the freight transportation: Modeling and pricing. Transp. Res. Part E Logist. Transp. Rev. 2015, 77, 95-114. [CrossRef]

70. Liimatainen, H.; Arvidsson, N.; Hovi, I.B.; Jensen, T.C.; Nykänen, L. Road freight energy efficiency and $\mathrm{CO}_{2}$ emissions in the Nordic countries. Res. Transp. Bus. Manag. 2014, 12, 11-19. [CrossRef]

71. Morrison, G.; Roebuck, R.L.; Cebon, D. Effects of longer heavy vehicles on traffic congestion. Proc. Inst. Mech. Eng. Part C J. Mech. Eng. Sci. 2013, 228, 970-988. [CrossRef] 
72. Agbo, A.A.; Zhang, Y. Sustainable freight transport optimisation through synchromodal networks. Cogent Eng. 2017, 4, 1421005. [CrossRef]

73. Crainic, T.G.; Ricciardi, N.; Storchi, G. Advanced freight transportation systems for congested urban areas. Transp. Res. Part C Emerg. Technol. 2004, 12, 119-137. [CrossRef] 